\title{
Surgical Treatment of Metabolic Syndrome
}

\author{
Norbert Runkel Rainer Brydniak \\ Department of General Surgery, Schwarzwald-Baar Hospital, Villingen-Schwenningen, Germany
}

Keywords

Obesity surgery - Metabolic surgery - Bariatric surgery . Metabolic syndrome - Type 2 diabetes mellitus .

Sleeve gastrectomy · Gastric bypass - Biliopancreatic diversion - Duodenal switch

\section{Summary}

Background: Bariatric surgery is gastrointestinal surgery for weight control, and metabolic surgery refers to the use of surgery to primarily and purposely treat type 2 diabetes mellitus (T2DM)/metabolic syndrome mellitus. Methods: The most recent literature was reviewed for surgery and T2DM in a non-systematic fashion. Results: Roux-Y gastric bypass, biliopancreatic diversion with duodenal switch, and sleeve gastrectomy (SG) are the dominant procedures today. SG is emerging as the most popular operation worldwide. Laparoscopy has made metabolic surgery as safe as other common abdominal procedures. A BMI > $60 \mathrm{~kg} / \mathrm{m}^{2}$, however, exposes a significantly higher perioperative risk. Most patients experience a sustained improvement of glycemic control with subsequent reduction of cardiovascular events. The remission rates depend on the severity and duration of diabetes. Prevention of long-term nutritional deficits and monitoring of metabolism require lifelong medical surveillance of the patients. Conclusions: The profound impact of weight reduction surgery on glucose metabolism explains the growing interest in treating T2DM by surgical means. Metabolic surgery is a safe option for carefully selected patients with metabolic syndrome.

(C) 2016 S. Karger GmbH, Freiburg

\section{Introduction}

Metabolic surgery has its roots in weight loss surgery, the story of which was told by the American Society for Metabolic and Bariatric Surgery (ASMBS) in 2004 [1]. It started in the 1950s with a jejunoileal bypass and was followed by a jejunocolic shunt some years later. Both procedures have not withstood the test of time because of inherent life-threatening, long-term nutritional derangements. They were replaced by the gastric bypass which was first described by Mason and Ito at the University of Iowa in 1965. A breakthrough in terms of feasibility, patient safety, and recovery was the introduction of minimally invasive techniques by Wittgrove in the year 1994. Currently, several variations exist regarding the length of intestinal limbs and the size of pouch. In 1979, Scopinaro invented biliopancreatic diversion (BPD) for stronger malabsorption. Today's standard is BPD with duodenal switch (DS) as introduced by Hess in 1986. Although BPD-DS is the most effective metabolic procedure, it is infrequently used because of high rates of postoperative and long-term complications. Laparoscopic sleeve gastrectomy (SG) was initially considered as the first of a multi-step bariatric concept for super-obese patients. It became apparent soon that SG was an effective standalone procedure for weight loss and remission of diabetes. Because of its ease and effectiveness, SG is becoming the most common operative procedure worldwide.

Originally conceived as an attempt to merely treat morbid obesity and improve cosmetic appearance, bariatric surgery has undergone an evolutionary development throughout the years, allowing it to be now recognized as a valued surgical treatment for obesity in conjunction with its correlated metabolic complications, e.g. type 2 diabetes mellitus (T2DM). The term metabolic surgery was introduced by Richard L. Varco and Henry Buchwald in 1978, who published a book with this title in which they defined this surgery as 'the operative manipulation of a normal organ system to achieve a biological result for a potential health gain' [2]. Since then, reversing metabolic complications of obesity has achieved a higher priority than weight loss per se. The modern term metabolic surgery is

\section{KARGER}

(๑) 2016 S. Karger GmbH, Freiburg

Fax +497614520714
Prof. Dr. Norbert Runkel 
employed in this article to indicate the use of gastrointestinal surgery to primarily and purposely treat metabolic disorders rather than to simply strive for body weight reduction. Using this definition, Roux-Y gastric bypass (RYGB) and its variants BPD-DS and SG are considered as standard metabolic operations by the authors, excluding gastric banding from this list because it lacks a weight loss-independent metabolic effect. This definition is a tighter one than that used by others $[3,4]$. Buchwald considers all bariatric procedures as metabolic and thus advocates the term bariatric/metabolic surgery [4]. He has identified six historically dominant procedures: jejunoileal bypass, vertical banded gastroplasty, adjustable gastric banding, RYGB, BPD and its American cousin DS, and SG.

\section{Indication for Bariatric and Metabolic Surgery}

The traditional classification of obesity was based on body mass index (BMI). Therefore, BMI has been the standard selection criterion for surgery since the National Institute of Health (NIH) consensus statement in 1991, with the NIH being the first organization issuing recommendations in this field [5]. Surgical intervention was considered suitable for those subjects with a BMI exceeding $40 \mathrm{~kg} /$ $\mathrm{m}^{2}$ or $\geq 35 \mathrm{~kg} / \mathrm{m}^{2}$ plus an obesity-related disease (i.e. T2DM, obesityinduced cardiomyopathy, severe osteoarthritis, severe sleep apnea, etc.) who, despite changes in lifestyle and adequate pharmacological therapy, have failed to control obesity and its comorbidities.

Subsequently, other organizations published BMI-centered guidelines varying in some aspects. The evidence-based recommendations from the German Society for General and Visceral Surgery (DGAV) are currently under revision [6, 7]. Even the most recent interdisciplinary German consensus from 2014 is a modification of the original NIH paper [8]. It includes the recommendation by the International Federation of Diabetes from the year 2011 that surgical management is applicable for patients with a BMI between 30 and $35 \mathrm{~kg} / \mathrm{m}^{2}$ who have an uncontrolled diabetes $\left(\mathrm{HbA}_{1 \mathrm{c}}\right.$ $>7.5 \%$ or $58 \mathrm{mmol} / \mathrm{ml}$ ) or other comorbidities (i.e. dyslipidemia, hypertension, etc.) [9].

There is little doubt about the relationship between excessive weight and metabolic diseases; however, there are numerous obese individuals without metabolic comorbidities as well as many normal-weight persons with increased metabolic and cardiovascular risks. Subjects with a BMI $\geq 30 \mathrm{~kg} / \mathrm{m}^{2}$ without the presence of T2DM, dyslipidemia, or hypertension are named metabolically healthy obese (MHO), but there is no generally accepted definition of this phenomenon. The prevalence of $\mathrm{MHO}$ is estimated to range between 10 and 34\% [10], decreasing somewhat with age. MHO appears to be more prevalent in women than in men. At present, it is not quite clear whether obesity without metabolic comorbidities will eventually convert into obesity with cardiovascular risk and, thus, whether MHO represents a unique subset of patients or an early snapshot of a progressive metabolic disease [11]. It is also unclear whether MHO and metabolically unhealthy obese patients require different therapeutic approaches to control weight. Both groups are equally well amenable to bariatric surgery.
In 2009, comorbidities and functional restrictions were put into the foreground by a new grading system of obesity by Sharma and Kushner [12]. The Edmonton Obesity Staging System (EOSS) classifies obesity into five stages according to the patient's medical, mental, and functional symptoms (table 1). The EOSS appears to be a better predictor of weight-related mortality than BMI. In health care systems with restricted access to metabolic surgery, EOSS may be used to prioritize overweight patients.

In collaboration with leading diabetes organizations and endorsed by a large group of international societies, the Second Diabetes Surgery Summit (DSSII) was held in London in September 2015. The objective of the DSSII conference was to develop Delphi consensus guidelines for the selection of T2DM patients as candidates for metabolic surgery [13]. The DSSII advocates for metabolic surgery in class 1 obesity. Surgery should be considered as an option to treat T2DM in patients with a BMI $<35 \mathrm{~kg} / \mathrm{m}^{2}$ if patients are poorly controlled despite optimal medical treatment [4]. The DSSII states that the vast majority of diabetic patients have a BMI < $35 \mathrm{~kg} / \mathrm{m}^{2}$ and that denying surgery to those who may benefit greatly is condemning millions of patients to the risk of micro- and macrovascular disease of uncontrolled T2DM despite best medical care. The novelty of these new guidelines is that they address $\mathrm{T} 2 \mathrm{DM}$ as a devastating, chronic, and progressive disease. Moreover, the guidelines are based on the severity and control (or lack of) of T2DM and not solely on the relation to weight and height of each particular individual.

Settling metabolic surgery as a new discipline and providing guidelines does not replace the indication for bariatric surgery. Too many severely obese patients are still in need of bariatric surgery in order to improve comorbidities other than T2DM, such as gastroesophageal reflux disease and osteoarthrosis, i.e., conditions that may remit after massive weight loss.

\section{Standard Techniques}

\section{Sleeve Gastrectomy}

SG is performed using 5 trocars, but other variations have been described such as 3 trocars, single-incision laparoscopic surgery, or robotic access. Retraction of the left liver gives way to the proximal stomach. The gastrocolic and the gastrosplenic ligaments are dissected from the greater curvature by using a sealing device such as an ultrasonic dissector. Clips may be additionally used to close bleeding vessels. It is of upmost importance that the dorsal fundus is completely mobilized so that the lesser curvature of the proximal stomach can be visualized from its backside. This guarantees a correct tubularization up to the esophagus. Gastric dissection along the greater curvature starts at about 3-5 cm proximal to the pylorus. A calibrating bougie is transorally advanced into the stomach. Its size has been a matter of debate. Today, a size of 32-36 French is considered standard. Gastric dissection is performed using linear staplers. Some prefer additional staple line reinforcements or a continuous suture. The staple line is checked for leaks by introducing methylene blue solution into the stomach. Occult 
Table 1. The Edmonton Obesity Staging System (EOSS) [12]

\begin{tabular}{|c|c|c|}
\hline Stage & Description & Management \\
\hline 0 & $\begin{array}{l}\text { No apparent obesity-related risk factors (e.g. blood pressure, serum } \\
\text { lipids, fasting glucose, etc. within normal range), no physical symptoms, } \\
\text { no psychopathology, no functional limitations and/or impairment of } \\
\text { well-being }\end{array}$ & $\begin{array}{l}\text { Identification of factors contributing to increased body weight. } \\
\text { Counseling to prevent further weight gain through lifestyle measures } \\
\text { including healthy eating and increased physical activity. }\end{array}$ \\
\hline 1 & $\begin{array}{l}\text { Presence of obesity-related subclinical risk factors (e.g. borderline } \\
\text { hypertension, impaired fasting glucose, elevated liver enzymes, etc.), } \\
\text { mild physical symptoms (e.g. dyspnea on moderate exertion, occasional } \\
\text { aches and pains, fatigue, etc.), mild psychopathology, mild functional } \\
\text { limitations and/or mild impairment of well-being }\end{array}$ & $\begin{array}{l}\text { Investigation for other (non-weight related) contributors to risk factors. } \\
\text { More intense lifestyle interventions, including diet and exercise to } \\
\text { prevent further weight gain. Monitoring of risk factors and health } \\
\text { status. }\end{array}$ \\
\hline 2 & $\begin{array}{l}\text { Presence of established obesity-related chronic disease (e.g. hyperten- } \\
\text { sion, type } 2 \text { diabetes, sleep apnea, osteoarthritis, reflux disease, } \\
\text { polycystic ovary syndrome, anxiety disorder, etc.), moderate limitations } \\
\text { in activities of daily living and/or well-being }\end{array}$ & $\begin{array}{l}\text { Initiation of obesity treatments including considerations of all } \\
\text { behavioral, pharmacological, and surgical treatment options. } \\
\text { Close monitoring and management of comorbidities as indicated. }\end{array}$ \\
\hline 3 & $\begin{array}{l}\text { Established end-organ damage such as myocardial infarction, heart } \\
\text { failure, diabetic complications, incapacitating osteoarthritis, significant } \\
\text { psychopathology, significant functional limitations and/or impairment } \\
\text { of well-being }\end{array}$ & $\begin{array}{l}\text { More intensive obesity treatment including consideration of all } \\
\text { behavioral, pharmacological, and surgical treatment options. Aggressive } \\
\text { management of comorbidities as indicated. }\end{array}$ \\
\hline 4 & $\begin{array}{l}\text { Severe (potentially end-stage) disabilities from obesity-related chronic } \\
\text { diseases, severe disabling psychopathology, severe functional limitations } \\
\text { and/or severe impairment of well-being }\end{array}$ & $\begin{array}{l}\text { Aggressive obesity management as deemed feasible. Palliative measures } \\
\text { including pain management, occupational therapy, and psychosocial } \\
\text { support. }\end{array}$ \\
\hline
\end{tabular}

staple line bleeding is checked by raising the blood pressure up to $140 \mathrm{~mm} \mathrm{Hg}$. A drain is placed at the angle of His.

\section{Roux-Y Gastric Bypass}

RYGB is performed using 5 trocars or, alternatively, 7,3 , or 1 . Robotic surgery has also been established in some centers. The aim of this method is a Roux-Y connection of the jejunum to a small gastric pouch. The order of surgical steps may vary between surgeons. The smaller curvature is carefully dissected $5 \mathrm{~cm}$ below the cardia without injuring the vagal nerves. The bursa omentalis is entered from here, and dorsal adhesions of the proximal stomach are taken down. Then, the peritoneum at the angle of His is incised. The first stapler is placed perpendicular to the smaller curvature. The next staplers are placed parallel to the curvature in the direction of the angle of His. A bougie is helpful for calibrating the pouch. Starting at the duodenojejunal angle, the biliary limb is measured up to $50 \mathrm{~cm}$ and divided. The alimentary limb is pulled upwards in front of the colon and stomach. A bulky omentum is divided longitudinally to reduce tension at the alimentary limb. The gastrojejunal anastomosis is performed using longitudinal or circular staplers or, rarely, suture techniques. The anastomosis of the biliary and the alimentary limb is created using stapling or hand-sewn techniques at $150 \mathrm{~cm}$ distal to the gastric anastomosis. Finally, the integrity of the gastrojejunostomy is checked by methylene blue test. Both mesenteric defects at the antecolic alimentary limb, the so-called Petersen space and the jejunojejunostomy space, are closed with running sutures to prevent internal hernias. A drain is placed close to the gastrojejunostomy.

\section{Biliopancreatic Diversion with Duodenal Switch}

BPD-DS was described in detail by Baltasar et al. [14] in 2001. Their technique is cited in the following. 6 trocars are used. The greater curvature of the stomach and the first part of the duodenum are completely devascularized with the harmonic scalpel. The duodenum is divided with a linear cutter. The vertical subtotal gastrectomy starts $7 \mathrm{~cm}$ proximal to the pylorus at the greater curvature by the serial application of linear cartridges parallel to the lesser curvature as far as the cardia. The gastric tube is filled with methylene blue to detect leaks. The resected stomach is removed through the $15-\mathrm{mm}$ port. The bowel is divided with a linear cutter $250 \mathrm{~cm}$ proximal to the ileocecal valve to form the alimentary limb. The mesentery is partially divided with the harmonic scalpel. The biliopancreatic and the alimentary limb are hand-sutured side-toend $75 \mathrm{~cm}$ proximal to the ileocecal valve. The duodenoileal endto-end anastomosis is hand-sutured or done by circular stapling. The mesenteric defects are left open.

\section{Choice of Procedure}

There are no evidence-based algorithms for the best choice of procedure. The choice of surgery should thus be tailored to each single individual according to the grade of obesity, the presence, type, and severity of comorbidities, the patient's wish, the surgeon's experience, and the patient's adherence. The recent DSSII statements are as follows [4]: RYGB is a well-standardized surgical procedure, and among the accepted operations for metabolic surgery it appears to have a more favorable risk-benefit profile in most pa- 
tients with T2DM. SG is considered effective with excellent weight loss and major improvement of T2DM, although longer-term studies ( $>3$ years) are less available when compared to RYGB. It could be a valuable option to treat diabetes, especially in patients for whom concerns exist over the risk of operations involving bowel diversion. Although clinical evidence suggests that BPD-DS may be the most effective procedure, the operation is associated with significant risk of nutritional deficiencies, making its risk-benefit profile less favorable than that of the other bariatric/metabolic procedures for most patients. BPD-DS should be considered only in patients with extreme levels of obesity (e.g. BMI $>60 \mathrm{~kg} / \mathrm{m}^{2}$ ).

\section{Effectiveness of Metabolic Surgery}

Data from 11 randomized controlled trials (RCTs) [15-26] in patients with T2D and a BMI $\geq 25 \mathrm{~kg} / \mathrm{m}^{2}\left(\right.$ mostly $\left.>35 \mathrm{~kg} / \mathrm{m}^{2}\right)$ and from a recent meta-analysis [27] consistently demonstrate superior efficacy of bariatric/metabolic surgery in reducing weight and lowering glycemia compared with a variety of medical/lifestyle interventions. However, the majority of these RCTs have only examined 1- to 2-year results, and only few have examined results for 3-5 years. The long-term results remain less clear with decreasing benefits over time, with or without weight regain. The famous Swedish SOS observational study confirmed a sustained favorable effect on glycemia up to 20 years [28].

A significant $\mathrm{HbA}_{1 \mathrm{c}}$ reduction of $2 \%$ can be seen after surgery versus $0.5 \%$ after conventional therapies, and the final $\mathrm{HbA}_{1 \mathrm{c}}$ in the surgical groups is near $6 \%$, regardless of the level of baseline $\mathrm{HbA}_{1 \mathrm{c}}$ [4]. The literature shows sustained diabetes remission in $30-63 \%$ of patients. Disease may recur over time in $35-50 \%$ or more of patients who initially achieve remission. Even after relapsing T2DM, the large majority of patients maintain substantial improvement of glycemic control from baseline for at least 5-15 years. One may assume that progression of macro- and microvascular complications of diabetes may be halted accordingly. Duration of diabetes, grade of diabetes therapy (use of insulin), and poor glycemic control are negative prognostic parameters regarding diabetes remission [29].

Retrospective studies and a recent prospective multicenter nonrandomized study suggest that metabolic surgery induces similar degrees of weight loss, diabetes remission, and improvement of cardiometabolic risk factors for at least 3 years after surgery in adolescents with T2DM [30].

Success of bariatric surgery traditionally means a loss of $>50 \%$ of excess weight. There is, however, no universally accepted definition of successful surgical treatment of T2DM. In 2009, an American Diabetes Association expert panel defined partial and complete remission of $\mathrm{T} 2 \mathrm{D}$ as the achievement of an $\mathrm{HbA}_{1 \mathrm{c}}<6.5$ and $<6.0 \%$, respectively, absence of all diabetes medications, and maintenance of these glycemic levels for at least 1 year [30]. Most obesity surgeons feel that total remission should not be the only measure of success; instead, even temporary normoglycemia, significant improvement of glycemic control, and downgrading of medication are meaningful benefits which justify metabolic surgery [31].
Table 2. Postoperative mortality as well as early ( $\leq 30$ days) and late ( $>30$ days) morbidity calculated from the literature by Castagneto Gissey et al. [32]

\begin{tabular}{lcrc}
\hline & SG & RYGB & BPD \\
\hline Postoperative mortality, \% & 0.42 & 0.37 & 1.2 \\
Early complications, \% & 5.46 & 5.91 & 5.60 \\
Late complications, \% & 7.70 & 17.54 & 13.70 \\
Reoperations, \% & 3.14 & 7.35 & 3.70 \\
\hline
\end{tabular}

$\mathrm{SG}=$ Sleeve gastrectomy RYGB = proximal Roux-Y bypass BPD = biliopancreatic diversion.

\section{Safety of Metabolic Surgery}

Safety of SG and RYGB has significantly improved with the introduction of laparoscopic techniques, standardization of methods and perioperative care, enhanced training and credentialing, and involvement of multidisciplinary teams. Morbidity has fallen to about $15 \%$ for minor and to $5 \%$ for major complications in this high-risk obese patient group, comparing favorably with other commonly performed elective operations (table 2). Mortality rates have dropped to less than $0.5 \%$, similar to cholecystectomy or hip replacement. BPD-DS represents the most complex procedure, requires longer operative time, and is associated with the highest perioperative mortality and morbidity rates.

Known risk factors of obesity surgery are higher age, super-obesity, male gender, multiple comorbidities, and previous or revisional bariatric operations. DeMaria et al. [33] presented a simple 3 -grade scoring system to stratify the mortality risk for patients undergoing gastric bypass based upon five independent variables: $\mathrm{BMI} \geq 50 \mathrm{~kg} / \mathrm{m}^{2}$, male gender, hypertension, pulmonary embolism risk, and age $\geq 45$ years. Mortality was low ( $0.31 \%$ class A), intermediate ( $1.90 \%$ class B), and high ( $7.56 \%$ class $\mathrm{C})$ [33].

The importance of the EOSS in predicting postoperative outcome and 30-day mortality after metabolic surgery was addressed by Chiappetta et al. [34], analyzing the outcome in 534 bariatric patients. The postoperative complication rates were $8.22 \%$ for EOSS 2 and 22.39\% for EOSS 3. The EOSS score was more accurate for predicting postoperative complications than other scores and may be used for presurgical stratification and risk assessment in clinical practice. Surgery seems to achieve the best results in EOSS grade 2 patients with regard to the prevention of metabolic sequelae and postoperative morbidity.

Long-term nutritional deficiencies, such as anemia, bone demineralization, and hypoproteinemia, may occur with variable frequency depending on the type of procedure, requiring lifelong vitamin/nutritional supplementation. Iron deficiency and anemia are very frequent. Nutritional complications are more frequent with BPD-DS, and less common/severe with RYGB or SG. Postprandial dumping and hypoglycemia can also occur, especially with RYGB, and can be managed with conservative therapy in most cases. New-onset reflux esophagitis is a typical complication after SG. Pre-existing reflux may be a contraindication to SG. 
The DSSII panel recommends lifelong postoperative surveillance of the development and/or progression of microvascular complications of T2DM (e.g. retinopathy, nephropathy, and neuropathy) by primary care physicians, endocrinologists, and internal medicine specialists as appropriate [4].

\section{Disclosure Statement}

The authors declare no possible conflicts of interest relating to their manuscript.

\section{References}

1 ASMBS: The Story of Obesity Surgery. https://asmbs. org/resources/story-of-obesity-surgery.

2 Buchwald H, Varco RL (eds): Metabolic Surgery. New York, Grune and Stratton, 1978.

3 Buchwald H: The evolution of metabolic/bariatric surgery. Obes Surg 2014;24:1126-1135.

4 Rubino F, Nathan DM, Eckel RH, Schauer PR, Alberti KG, Zimmet PZ, Del Prato S, Ji L, Sadikot SM, Herman WH, Amiel SA, Kaplan LM, Taroncher-Oldenburg G, Cummings DE; Delegates of the 2nd Diabetes Surgery Summit: Metabolic surgery in the treatment algorithm for type 2 diabetes: a joint statement by international diabetes organizations. Diabetes Care 2016; 39:861-877.

5 NIH conference. Gastrointestinal surgery for severe obesity. Consensus Development Conference Panel. Ann Intern Med 1991;115:956-961.

6 Runkel N, Colombo-Benkmann M, Hüttl TP, Tigges H, Mann O, Sauerland S: Bariatric surgery. Dtsch Arztebl Int 2011;108:341-346.

7 Runkel N, Colombo-Benkmann M, Hüttl TP, Tigges H, Mann O, Flade-Kuthe R, Shang E, Susewind M, Wolff S, Wunder R, Wirth A, Winckler K, Weimann A, de Zwaan M, Sauerland S: Evidence-based German guidelines for surgery for obesity. Int J Colorectal Dis 2011;26:397-404.

8 Interdisziplinäre Leitlinie Qualität S3 «Prävention und Therapie der Adipositas». www.adipositas-gesellschaft.de/ fileadmin/PDF/Leitlinien/S3_Adipositas_Praevention_ Therapie_2014.pdf.

9 Dixon JB, Zimmet P, Alberti KG, Rubino F; International Diabetes Federation Taskforce on Epidemiology and Prevention: Bariatric surgery: an IDF statement for obese type 2 diabetes. Diabet Med 2011;28:628642 .

10 Roberson LL, Aneni EC, Maziak W, Agatston A, Feldman T, Rouseff M, Tran T, Blaha MJ, Santos RD, Sposito A, Al-Mallah MH, Blankstein R, Budoff MJ, Nasir $\mathrm{K}$ : Beyond BMI: the 'metabolically healthy obese' phenotype \& its association with clinical/subclinical cardiovascular disease and all-cause mortality - a systematic review. BMC Public Health 2014;14:14.

11 Muñoz-Garach A, Cornejo-Pareja I, Tinahones FJ: Does metabolically healthy obesity exist? Nutrients 2016;8:pii: E320.

12 Sharma AM, Kushner RF: A proposed clinical staging system for obesity. Int J Obes (Lond) 2009;33:289-295.

13 Cohen RV, Shikora S, Petry T, Caravatto PP, Le Roux CW: The Diabetes Surgery Summit II Guidelines: a Disease-Based Clinical Recommendation. Obes Surg 2016;26:1989-1991.
14 Baltasar A, Bou R, Miró J, Bengochea M, Serra C, Pérez $\mathrm{N}$ : Laparoscopic biliopancreatic diversion with duodenal switch: technique and initial experience. Obes Surg 2002;12:245-248.

15 Dixon JB, O’Brien PE, Playfair J, et al: Adjustable gastric banding and conventional therapy for type 2 diabetes: a randomized controlled trial. JAMA 2008;299: 316-323.

16 Courcoulas AP, Goodpaster BH, Eagleton JK, et al: Surgical vs medical treatments for type 2 diabetes mellitus: a randomized clinical trial. JAMA Surg 2014;149: 707-715.

17 Halperin F, Ding SA, Simonson DC, et al: Roux-en-Y gastric bypass surgery or lifestyle with intensive medical management in patients with type 2 diabetes: feasibility and 1-year results of a randomized clinical trial. JAMA Surg 2014;149:716-726.

18 Liang Z, Wu Q, Chen B, Yu P, Zhao H, Ouyang X: Effect of laparoscopic Roux-en-Y gastric bypass surgery on type 2 diabetes mellitus with hypertension: a randomized controlled trial. Diabetes Res Clin Pract 2013; 101:50-56.

19 Wentworth JM, Playfair J, Laurie C, et al: Multidisciplinary diabetes care with and without bariatric surgery in overweight people: a randomised controlled trial. Lancet Diabetes Endocrinol 2014;2:545-552.

20 Parikh M, Chung M, Sheth S, et al: Randomized pilot trial of bariatric surgery versus intensive medical weight management on diabetes remission in type 2 diabetic patients who do NOT meet NIH criteria for surgery and the role of soluble RAGE as a novel biomarker of success. Ann Surg 2014;260:617-622; discussion 622-624.

21 Schauer PR, Bhatt DL, Kirwan JP, et al.; STAMPEDE Investigators: Bariatric surgery versus intensive medical therapy for diabetes - 3-year outcomes. N Engl J Med 2014;370:2002-2013.

22 Mingrone G, Panunzi S, De Gaetano A, et al: Bariatricmetabolic surgery versus conventional medical treatment in obese patients with type 2 diabetes: 5 year follow-up of an open-label, single-centre, randomised controlled trial. Lancet 2015;386:964-973.

23 Ikramuddin S, Billington CJ, Lee WJ, et al: Roux-en-Y gastric bypass for diabetes (the Diabetes Surgery Study): 2-year outcomes of a 5-year, randomised, controlled trial. Lancet Diabetes Endocrinol 2015;3:413422.

24 Ding SA, Simonson DC, Wewalka M, et al: Adjustable gastric band surgery or medical management in patients with type 2 diabetes: a randomized clinical trial. J Clin Endocrinol Metab 2015;100:2546-2556.
25 Cummings DE, Arterburn DE, Westbrook EO, et al: Gastric bypass surgery vs intensive lifestyle and medical intervention for type 2 diabetes: the CROSSROADS randomised controlled trial. Diabetologia 2016;59: 945-953.

26 Courcoulas AP, Belle SH, Neiberg RH, et al: Threeyear outcomes of bariatric surgery vs lifestyle intervention for type 2 diabetes mellitus treatment: a randomized clinical trial. JAMA Surg 2015;150:931-940.

27 Müller-Stich BP, Senft JD, Warschkow R, Kenngott HG, Billeter AT, Vit G, Helfert S, Diener MK, Fischer L, Büchler MW, Nawroth PP: Surgical versus medical treatment of type 2 diabetes mellitus in nonseverely obese patients: a systematic review and meta-analysis. Ann Surg 2015;261:421-429.

28 Sjöström L, Peltonen M, Jacobson P, Ahlin S, Andersson-Assarsson J, Anveden Å, Bouchard C, Carlsson B, Karason K, Lönroth H, Näslund I, Sjöström E, Taube M, Wedel H, Svensson PA, Sjöholm K, Carlsson LM: Association of bariatric surgery with long-term remission of type 2 diabetes and with microvascular and macrovascular complications. JAMA 2014;311:22972304.

29 Runkel M, Müller S, Brydniak R, Runkel N: Downgrading of type 2 diabetes mellitus (T2DM) after obesity surgery: duration and severity matter. Obes Surg 2015;25:494-499.

30 Inge TH, Courcoulas AP, Jenkins TM, et al.; TeenLABS Consortium: Weight loss and health status 3 years after bariatric surgery in adolescents. N Engl Med 2016;374:113-123.

31 Buse JB, Caprio S, Cefalu WT, et al: How do we define cure of diabetes? Diabetes Care 2009;32:2133-2135.

32 Castagneto Gissey L, Casella Mariolo JR, Mingrone G: How to choose the best metabolic procedure? Curr Atheroscler Rep 2016;18:43.

33 DeMaria EJ, Portenier D, Wolfe L: Obesity surgery mortality risk score: proposal for a clinically useful score to predict mortality risk in patients undergoing gastric bypass. Surg Obes Relat Dis 2007;3:134-140.

34 Chiappetta S, Stier C, Squillante S, Theodoridou S, Weiner RA: The importance of the Edmonton Obesity Staging System in predicting postoperative outcome and 30-day mortality after metabolic surgery. Surg Obes Relat Dis 2016;pii: S1550-7289(16)00088-5. 